\title{
Comparison of asthma treatment given in addition to inhaled corticosteroids on airway inflammation and responsiveness
}

\author{
R.H. Green*, C.E. Brightling*, S. McKenna*, B. Hargadon*, N. Neale*, D. Parker*, \\ C. Ruse*, I.P. Hall ${ }^{\#}$ and I.D. Pavord*
}

ABSTRACT: There is increasing evidence that the assessment of eosinophilic airway inflammation using induced sputum and measurement of airway hyperresponsiveness provides additional, clinically important information concerning asthma control. The aim of this study was to directly compare the effects of different treatments on these markers in patients with asthma and persistent symptoms, despite the use of low-dose inhaled corticosteroids.

A double-blind four-way crossover study was performed, which compared a 1-month treatment with budesonide $400 \mu \mathrm{g}$ b.i.d., additional formoterol, additional montelukast and placebo in 49 patients with uncontrolled asthma despite budesonide $100 \mu \mathrm{g}$ b.i.d., with each treatment separated by a 4-week washout period.

The change in sputum eosinophil count with formoterol $(2.4$ to $3.8 \%$ change, 0.6 -fold reduction, 95\% confidence interval $(\mathrm{Cl}) 0.5-0.9)$ differed significantly from placebo (2.8 to $2.5 \%$ change, $1.1-$ fold reduction, $95 \% \mathrm{Cl} 0.7-1.6)$ and high-dose budesonide (2.7 to 1.6\% change, 1.6-fold reduction, 95\% Cl 1.2-2.2). The effects of montelukast did not differ from placebo. The changes in methacholine airway responsiveness were small and did not differ between treatments. High-dose budesonide had the broadest range of beneficial effects on other outcomes, including symptom scores, morning peak expiratory flow and forced expiratory volume in one second.

In conclusion, treatment given in addition to low-dose inhaled corticosteroids results in modest benefits. Formoterol and high-dose budesonide have contrasting effects on eosinophilic airway inflammation.

KEYWORDS: Asthma, inhaled corticosteroids, leukotriene antagonists, long-acting $\beta_{2}$-agonists, treatment

considerable number of patients with asthma remain symptomatic despite treatment with low-dose inhaled corticosteroids. A large, primary care-based audit by NeVILLE et al. [1] showed that nearly half of all patients were taking low-dose inhaled corticosteroids in addition to as required $\beta_{2}$-agonists and that $54 \%$ of these were taking more than two puffs of a $\beta$-agonist per day, suggesting the need for a treatment step-up [1].

Presently, the clinician is faced with an increasing number of treatment options for this important group of patients, but relatively little data from placebo-controlled comparative studies to guide treatment decisions.

Many of the available studies examining the effect of treatment options after low-dose inhaled corticosteroids have assessed the effects of treatment on measures of lung function and symptoms [2-6]. However, recent studies have suggested that the assessment of eosinophilic airway inflammation $[7,8]$ and airway responsiveness [9] provides additional, clinically important information on asthma control. No placebocontrolled study has assessed the effects of different treatment options after low-dose inhaled corticosteroids on these important markers of asthma control.

The current authors' aims were to directly compare the effects of higher-dose budesonide, low-dose budesonide plus formoterol and lowdose budesonide plus montelukast on the induced sputum eosinophil count and methacholine airway responsiveness in a prospective, double-blind, placebo-controlled, four-way crossover study of patients with symptomatic asthma who met the criteria to warrant an increase in
AFFILIATIONS

*Institute for Lung Health, Dept of Respiratory, Medicine and Thoracic Surgery, Glenfield Hospital,

Leicester, and

\#Division of Therapeutics, Queens Medical Centre, Nottingham, UK.

\section{CORRESPONDENCE}

R.H. Green

Institute for Lung Health

Dept of Respiratory Medicine and

Thoracic Surgery

Glenfield Hospital

Groby Road

Leicester LE3 9PQ

UK

Fax: 441162367768

E-mail: ruth.green@uhl-tr.nhs.uk

Received:

September 012005

Accepted after revision:

January 192006

SUPPORT STATEMENT

The study was supported by funding from Asthma UK. 
treatment. A secondary aim was to identify variables that might be associated with the response to treatment.

\section{METHODS \\ Subjects}

Volunteers aged 18-75 yrs, diagnosed with asthma and being treated with the equivalent of $\leqslant 400 \mu \mathrm{g} \cdot$ day $^{-1}$ beclomethasone dipropionate, were invited to participate in the study, following advertisements in the local media. Subjects were excluded if they were current smokers or had a smoking history of $>10$ pack-yrs, had significant comorbidity, were receiving oral corticosteroids, long-acting $\beta_{2}$-agonists, leukotriene antagonists or theophylline, or had undergone an asthma exacerbation or lower respiratory tract infection within the 4 weeks prior to trial entry. All patients had symptoms consistent with the diagnosis of asthma and one or more of the following: 1) a $>15 \%$ increase in forced expiratory volume in one second (FEV1) following $200 \mu \mathrm{g}$ of inhaled salbutamol; 2) $>20 \%$ within-day variability in peak expiratory flow (PEF) assessed twice daily over a 2-week period; or 3) a provocative concentration of methacholine causing a $20 \%$ fall in FEV1 (PC20) $<8 \mathrm{mg} \cdot \mathrm{mL}^{-1}$. Subjects were established on a standard dose of budesonide (100 $\mu \mathrm{g}$ b.i.d. via a turbohaler) for 4 weeks before entry and were eligible to participate in the study if they had recorded day- or night-time asthma symptoms on their diary cards on at least 4 days in the third or fourth baseline week. The local research ethics committee approved the study and all patients gave written informed consent.

\section{Measurements}

Allergen skin-prick tests were performed for Dermatophagoides pteronyssinus, cat fur, grass pollen and Aspergillus fumigatus solutions with normal saline and histamine controls (AlkAbelló, Berkshire, UK). End-exhaled nitric oxide (NO) was measured with a chemiluminescence analyser (Logan Research, Rochester, UK) with subjects exhaling at a flow rate of $250 \mathrm{~mL} \cdot \mathrm{s}^{-1}$. NO was sampled from a sidearm attached to the mouthpiece and the mean NO value was taken from the point corresponding to the plateau of the end-exhaled carbon dioxide reading [9]. Methacholine challenge testing was performed using the tidal breathing method with doubling concentrations of methacholine $\left(0.03-16 \mathrm{mg} \cdot \mathrm{mL}^{-1}\right)$ nebulised via a Wright nebuliser [10]. FEV1 before and $20 \mathrm{~min}$ after $200 \mu \mathrm{g}$ of salbutamol was inhaled was recorded on different occasions, separated by at least $48 \mathrm{~h}$ from the methacholine challenge. Symptoms over the previous week of treatment were recorded on 100-mm visual analogue scales (VAS) from no symptom $(0 \mathrm{~mm})$ to the most severe symptom $(100 \mathrm{~mm})$ for breathlessness, wheeze and cough. The total VAS score (0$300 \mathrm{~mm}$ ) was calculated as the sum of the three individual scores [7]. The JUNIPER et al. [11] Asthma Quality of Life Questionnaire (AQLQ) was used to assess asthma-specific quality of life. Sputum was induced and processed as previously described [12]. An experienced observer blinded to the study medication and clinical characteristics performed the cell counts. The cell free sputum supernatant was removed and stored at $-80^{\circ} \mathrm{C}$ until analysis. The cysteinyl leukotrienes (LT) $\mathrm{C}_{4} / \mathrm{LTD}_{4} / \mathrm{LTE}_{4}$ were measured in the sputum supernatant using a commercial ELISA (Cayman Chemical, Ann Arbor, MI, USA) with the standard curve spiked with dithiothreitol at the same concentration as the unknown [13]. The intra- and inter-assay coefficients of variability were $<10 \%$ and the lower limit of detection was $13 \mathrm{pg} \cdot \mathrm{mL}^{-1}$ of sample.

Patients completed daily diary cards throughout the study, recording day- and night-time symptoms, twice daily PEF and rescue $\beta_{2}$-agonist use. Day- and night-time symptom scores were recorded on a four-point scale as previously described [2, 7]. PEF was recorded as the best of three successive readings using a Mini-Wright peak flow meter (Clement Clarke International Ltd, Harlow, UK). Compliance was assessed by tablet counting and by assessment of turbohaler use; it was defined as acceptable if the subjects used $>75 \%$ of the recommended dose of study drug or placebo.

In a subgroup of 37 patients who gave their consent, the current authors determined the genotype at the $\beta_{2}$-adrenoceptor by allele-specific oligonucleotide hybridisation of genomic DNA extracted from a 5-mL sample of whole blood, as previously described [14, 15].

\section{Study design}

A randomised, double-blind, placebo-controlled, four-way crossover study was performed. After recruitment, baseline measurements were recorded and then patients underwent a 1-month run-in period during which they took budesonide $100 \mu \mathrm{g}$ b.i.d. via a turbohaler along with salbutamol as required for symptom relief. The patients then attended the clinic for measurement of exhaled NO, spirometry, methacholine PC20, AQLQ, VAS symptom scores and sputum induction (in this order). Suitable subjects were randomised to receive one of the following for a period of 1 month: 1) budesonide $100 \mu \mathrm{g}$ b.i.d. alone; 2) budesonide $400 \mu \mathrm{g}$ b.i.d.; 3) budesonide $100 \mu \mathrm{g}$ b.i.d. and oral montelukast $10 \mathrm{mg}$ q.d.; and 4) budesonide $100 \mu \mathrm{g}$ b.i.d. and inhaled formoterol $12 \mu \mathrm{g}$ b.i.d. All inhaled study medication was delivered via a turbohaler. Blinding was maintained by issuing two identical turbohalers containing active and placebo formoterol and 100 or $400 \mu \mathrm{g}$ budesonide (AstraZeneca, Lund, Sweden) and montelukast and placebo tablets were each prepared in a single white capsule (Royal Hallamshire Hospital Pharmacy Department, Sheffield, UK). Patients then completed a 1-month washout period during which they were maintained on budesonide $100 \mu \mathrm{g}$ b.i.d. given via an unblinded turbohaler and as required salbutamol only. At the end of this time, clinical measurements were repeated and patients crossed over to a second of the above four treatments, which they received for a further 1-month period. The process was then repeated until the subjects had received each of the four treatments, with a 4 -week washout period between each. Clinical measurements were taken at the same time of day, $12 \mathrm{~h}$ after the last dose of each treatment and at least $6 \mathrm{~h}$ after the last dose of short-acting $\beta_{2}$-agonist. The order of treatments was randomly allocated to each patient. Randomisation was performed by the Glenfield Hospital Pharmacy Dept Leicester, UK.

Severe asthma exacerbations were defined as a decrease in the morning PEF $>30 \%$ below the baseline value on $\geqslant 2$ consecutive days, or deterioration in symptoms requiring treatment with oral corticosteroids [2]. If a severe exacerbation occurred, this was treated with prednisolone $30 \mathrm{mg}$ q.d. for 2 weeks followed by a 6-week washout period of budesonide $100 \mu \mathrm{g}$ b.i.d. and as required salbutamol only. Patients who 


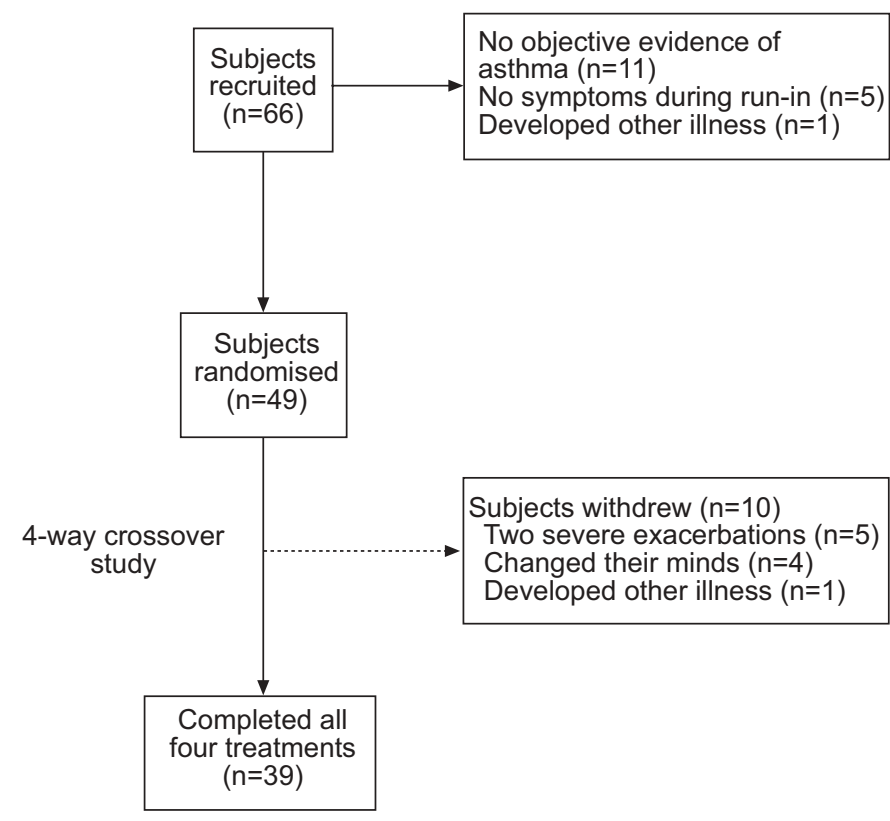

FIGURE 1. Trial profile.

experienced two severe exacerbations were withdrawn from the study.

\section{Statistical analysis}

The primary outcome variables were the change from the pretreatment baseline in the methacholine PC20 (in doubling concentrations), fold change in sputum eosinophil count and the change in global VAS symptom score. Secondary outcome measures were the change from the pre-treatment baseline in FEV1, total AQLQ score, fold change in exhaled NO and the change in morning PEF calculated as the mean change between the final week of the washout period and the final week of treatment. Based on a conservative estimate of within-subject standard deviation of one doubling dose, $10 \mathrm{~mm}$ and two-fold difference for methacholine PC20, symptom scores and sputum eosinophils $[10,16,17]$, a total of 40 patients were required for an $80 \%$ chance of detecting a one doubling-dose difference in change in methacholine PC20, a two-fold difference in sputum eosinophil count between treatment and a $20-\mathrm{mm}$ difference in total VAS symptom scores at the $5 \%$ level.

Patients who had a severe exacerbation during a treatment month were assigned the lowest observed value for the change in each outcome measure for that treatment. If a treatment was stopped early due to adverse effects, measurements were taken within $12 \mathrm{~h}$ of the last dose of treatment and the results were included on an intention-to-treat basis. Patients who withdrew from the study for reasons other than a severe exacerbation were assigned the mean value for the change in each outcome variable.

Induced sputum eosinophil counts, exhaled NO concentrations and methacholine PC20 were log 10 normally distributed and were expressed as the geometric mean $\pm \log 10$ SE. Age and age at onset were expressed as median (range). All other baseline variables were expressed as mean \pm SD. Primary and secondary outcome measures were compared between groups using a two-way ANOVA with the least significant difference test for multiple comparisons. Period and order effects were investigated using analysis of covariance. The current authors explored the relationship between baseline bronchodilator response, cysteinyl-leukotriene concentrations, sputum eosinophils and response to treatment using the Pearson correlation coefficient. The effect of $\beta_{2}$-adrenoceptor genotype and subsequent change in primary outcome variables was compared between placebo treatment and formoterol by an unpaired t-test. The Chi-squared test was used to compare the numbers of patients having severe asthma exacerbations during each of the treatment periods.

\section{RESULTS}

A total of 66 patients were recruited into the study, of which 49 were randomised. Ten patients withdrew early and therefore failed to complete one or more of the study treatments. Baseline demographic data and lung function are given in table 1. All subjects were judged to have acceptable compliance. There were no period or order effects and pre-treatment values were well matched for each outcome variable (table 2). The number of patients completing each treatment is given in figure 1 and table 3 . A total of 18 severe exacerbations occurred during the following treatment periods: washout periods $(n=7)$; high-dose budesonide $(n=1)$; formoterol $(n=2)$; montelukast $(n=4)$; and placebo $(n=4)$. The difference in exacerbation frequency between treatments was not significant $(\mathrm{p}=0.46)$.

\section{Primary outcome variables}

Sputum eosinophils

There was a significant difference in the fold change in the sputum eosinophil count across the groups $(p=0.005$; table 3 ; fig. 2.) The change in sputum eosinophil count with formoterol (2.4 to $3.8 \%$; 0.6 -fold reduction; $95 \%$ confidence interval (CI) $0.5-0.9)$ differed significantly from placebo (2.8 to $2.5 \%$; 1.1 fold reduction; 95\% CI 0.7-1.6; $\mathrm{p}=0.03$ ) and high-dose budesonide (2.7 to $1.6 \%$; 1.6 -fold reduction; $95 \%$ CI $1.2-2.2$; $\mathrm{p}<0.001)$.

\section{TABLE 1 Baseline characteristics}

Baseline characteristics

$\begin{array}{lc}\text { Patients } \mathbf{n} & 49 \\ \text { Male } \mathbf{n} & 25 \\ \text { Age yrs } & 42(19-73) \\ \text { Age at onset yrs } & 13.5(1-67) \\ \text { Atopic } \mathbf{n} & 37 \\ \text { FEV } \mathbf{1} \% \text { pred } & 74.8 \pm 3.1 \\ \text { FEV } \mathbf{1} \text { FVC ratio \% } & 67.6 \pm 2.2 \\ \text { Increase in FEV } \mathbf{1} \text { post-bronchodilator \% } & 13.2 \pm 1.5 \\ \text { >15\% increase in FEV } \mathbf{1} & 15 \\ \quad \text { post-bronchodilator } \mathbf{n} & \\ \text { PEF amplitude \% } & 13.1 \pm 1.4\end{array}$

Data are presented as $n$, median (range) or mean \pm SEM. FEV1: forced expiratory volume in one second; \% pred: \% predicted; FVC: forced vital capacity; PEF: peak expiratory flow. 
TABLE 2 Pre-treatment results

\begin{tabular}{|c|c|c|c|c|}
\hline & $\begin{array}{l}\text { High-dose } \\
\text { budesonide }\end{array}$ & $\begin{array}{l}\text { Low-dose plus } \\
\text { formeterol }\end{array}$ & $\begin{array}{c}\text { Low-dose plus } \\
\text { montelukast }\end{array}$ & $\begin{array}{l}\text { Low-dose plus } \\
\text { placebo }\end{array}$ \\
\hline Methacholine $\mathrm{PC}_{20} \mathrm{mg} \cdot \mathrm{mL}^{-1 \#}$ & $0.39 \pm 0.1$ & $0.37 \pm 0.1$ & $0.28 \pm 0.1$ & $0.29 \pm 0.1$ \\
\hline Sputum eosinophil count $\%^{\#}$ & $2.6 \pm 0.1$ & $2.2 \pm 0.1$ & $2.0 \pm 0.1$ & $2.8 \pm 0.1$ \\
\hline Daytime symptom scores $0-3$ & $0.56(0.08)$ & $0.58(0.08)$ & $0.61(0.09)$ & $0.62(0.07)$ \\
\hline Night-time symptom scores $0-3$ & $0.24(0.08)$ & $0.20(0.06)$ & $0.21(0.07)$ & $0.18(0.05)$ \\
\hline Symptom free days/weeks & $1.67(0.41)$ & $1.68(0.39)$ & $2.33(0.77)$ & $1.57(0.39)$ \\
\hline Rescue $\beta_{2}$-agonist use inhalations $\cdot$ day $^{-1}$ & $1.72(0.33)$ & $1.95(0.40)$ & $2.09(0.37)$ & $1.84(0.34)$ \\
\hline Morning PEF & $417 \pm 14$ & $423 \pm 12$ & $418 \pm 13$ & $418 \pm 14$ \\
\hline FEV $_{1} \mathrm{~L}$ & $2.52 \pm 0.1$ & $2.51 \pm 0.1$ & $2.54 \pm 0.1$ & $2.51 \pm 0.1$ \\
\hline
\end{tabular}

Data are presented as mean \pm SE. PC20: provocative concentration causing a 20\% fall in forced expiratory volume in forced expiratory volume in one second (FEV1); VAS visual analogue scales; PEF: peak expiratory flow; AQLQ: Asthma Quality of Life Questionnaire; eNO: exhaled nitric oxide. ${ }^{\#}$ : geometric mean \pm log $10 \mathrm{SE}$

\section{Methacholine PC20}

There were no significant differences in the doubling concentration change in methacholine $\mathrm{PC} 20$ between any of the treatment groups and placebo nor across the individual treatments (table 3; fig. 2).

\section{Symptom scores}

Higher-dose budesonide resulted in a significant improvement in the global VAS symptom score compared with low-dose budesonide plus placebo (mean difference $21.3 \mathrm{~mm}$; 95\% CI 39.8- -2.9; $\mathrm{p}=0.023$ ). Additional montelukast and additional formoterol did not result in significant improvements in VAS symptom scores compared with placebo and the difference across the four treatment arms was of borderline statistical significance ( $p=0.05$; table 3 ; fig. 2 ). There was no significant difference in the change in daytime symptom scores $(p=0.8)$, night-time symptom scores $(p=0.28)$, symptom-free days $(p=0.10)$ or rescue $\beta_{2}$-agonist use $(p=0.16)$ across the four treatment arms (table 3).

\section{Secondary outcome variables}

Morning peak expiratory flow

Significant differences in the change in mean morning PEF over the final week of treatment were observed across the four treatments $(p=0.019$; table 3$)$. A significant improvement in mean morning PEF was seen with both high-dose budesonide (16.3 $\mathrm{L} \cdot \mathrm{min}^{-1} ; 95 \%$ CI 3.8-28.8; $\mathrm{p}=0.01$ ) and additional formoterol $\left(17.2 \mathrm{~L} \cdot \mathrm{min}^{-1}\right.$; 95\% CI 4.7-29.7; $\left.\mathrm{p}=0.007\right)$ compared with placebo.

\section{Fold change in exhaled nitric oxide}

There was a significant difference in the fold change in exhaled nitric oxide (eNO) across the groups $(p=0.011$; table 3$)$. The change in eNO with high-dose budesonide differed significantly from the change seen with placebo (mean $(95 \% \mathrm{CI})$ difference $1.86(1.21-2.86)$ fold; $\mathrm{p}=0.005)$ and formoterol (mean (95\% CI) difference 1.95 (1.27-3.00) fold; $\mathrm{p}=0.003$ ).
Pre-bronchodilator FEV1

The difference in pre-bronchodilator FEV1 across the four treatment arms did not reach statistical significance $(p=0.133)$.

\section{Change in total AQLQ score}

There were no significant differences in the change in the total AQLQ score across the four treatments $(p=0.81)$.

\section{Subgroup analyses}

The response to any of the treatments studied was not influenced by atopic status, degree of acute bronchodilator reversibility, pre-treatment sputum eosinophil counts, or pre-treatment sputum cysteinyl-leukotriene concentrations. Compared with heterozygotes/Gly-Gly homozygotes $(n=19$ / $10)$, homozygous Arg-16 patients $(n=6)$ responded less well to formoterol (doubling dose change in PC20 -1.08 versus 1.05; mean $(95 \% \mathrm{CI})$ difference $-2.13(-0.04--4.2) ; \mathrm{p}=0.046$; change in FEV1 -0.38 versus $0.02 \mathrm{~L}$; mean difference 0.40 (0.09-0.71); $\mathrm{p}=0.014)$, but there was no difference in the change in sputum eosinophils $(2.2 \pm 0.1 \%$ to $3.1 \pm 0.2 \%$ compared with $3.8 \pm 0.3 \%$ to $13.2 \pm 0.3 \% ; p=0.14)$. In contrast, homozygous Gln-27 patients $(n=15)$ had a better anti-inflammatory response to high-dose inhaled steroids than heterozygotes/Glu-Glu homozygotes $(n=20 / 2$; fold reduction in sputum eosinophils 3.01 versus 1.25; mean difference 2.40 (1.14-5.01 concentration); $\mathrm{p}=0.023)$.

\section{DISCUSSION}

This is the first placebo-controlled comparison of the treatment options for patients with symptomatic asthma, despite lowdose inhaled corticosteroids and the first to examine the effect on airway inflammation and airway responsiveness. Overall, the benefit provided by each of the additional treatments on the primary outcome measures in this group of patients was minor; there was important heterogeneity of treatment response, particularly in the effects of treatment on eosinophilic airway inflammation. 
Recent studies have emphasised the importance of the measures chosen as the current study's primary outcomes by showing that management strategies that aim to normalise eosinophilic airway inflammation [7, 8] or airway hyperresponsiveness [9] are associated with important reductions in the frequency of asthma exacerbations. The present study was powered to show the effects that have been previously identified as being clinically significant [10, 17] and are equivalent, or greater, than have been shown to be associated with reduced exacerbation frequency $[7,9]$. In corticosteroidnaive asthma, the introduction of inhaled corticosteroid treatment results in 1-4 doubling dose improvements in airway responsiveness [16, 18] and 6-10-fold reductions in the sputum eosinophil count $[16,19]$. The much smaller effects seen in this study indicate that most patients who are symptomatic, despite taking low-dose inhaled corticosteroids, are near the top of the dose-response curve for these variables. The VAS symptom scores and morning PEF were more responsive in the current study, emphasising the complex relationship between airway inflammation, airway responsiveness, simple tests of airway calibre and clinical expression of the disease. It is possible that more clear evidence of efficacy would be apparent in a more symptomatic population, although all the present patients met current criteria for a step-up in treatment [20] and had day- and night-time symptom scores and impairment of lung function comparable to those seen in the Formoterol and Corticosteroids Establishing Therapy (FACET) study [2]. These factors suggest that the subjects included in the present study are likely to be representative of the wider population of patients in whom additional treatment has been evaluated. The patients who completed the present study had to remain free from exacerbations for 5 months on low-dose inhaled corticosteroids only; this factor should be considered when generalising the current findings to a wider population.
The relative efficacy of the treatments differed considerably with the different outcome variables studied. The most striking example of this can be seen with the contrasting effects of formoterol and high-dose budesonide on markers of eosinophilic airway inflammation. The current findings with formoterol contrast with those of KIPS et al. [21], who studied the effects of low-dose budesonide plus formoterol versus highdose budesonide on sputum inflammatory cells in a subset of the participants of the FACET study. They found a slight increase in the sputum eosinophil count in the budesonide plus formoterol group compared with the groups treated with higher-dose budesonide. This increase did not reach statistical significance, although there were clinically important differences in the level of eosinophilic airway inflammation in the two groups at baseline, which complicate the interpretation of these data. Bronchial biopsy studies of the effects of longacting $\beta_{2}$-agonists on airway inflammation in asthma have neither shown an increase in mucosal eosinophil numbers nor consistent evidence of anti-inflammatory effects [22-24]. One way to reconcile the current findings with those of the bronchial biopsy studies is that $\beta_{2}$-agonists increase trafficking of eosinophils away from the airway mucosa into the airway lumen rather than an increase in eosinophilic airway inflammation per se.

Eosinophilic airway inflammation has been implicated in the pathophysiology of severe asthma exacerbations [7, 25]. There were no significant differences in exacerbation frequency between the treatment arms in the present study, although it was not powered to show this. However, there is considerable evidence from appropriately designed studies that the addition of formoterol to inhaled corticosteroids is associated with a reduction in the frequency of asthma exacerbations [2, 3]. In contrast, the regular use of short-acting $\beta_{2}$-agonists has been associated with increased eosinophilic airway inflammation [26] and exacerbation frequency in some [27], but not all

TABLE 3 Change from baseline in primary and secondary outcome variables

\begin{tabular}{|c|c|c|c|c|}
\hline & High-dose & $\begin{array}{l}\text { Low-dose plus } \\
\text { formeterol }\end{array}$ & $\begin{array}{l}\text { Low-dose plus } \\
\text { montelukast }\end{array}$ & $\begin{array}{l}\text { Low-dose plus } \\
\text { placebo }\end{array}$ \\
\hline Patients completing treatment & 42 & 40 & 43 & 41 \\
\hline Methacholine $\mathrm{PC}_{20}$ doubling dose & $0.4(-0.2-1.0)$ & $0.2(-0.5-1.0)$ & $0.4(-0.3-1.0)$ & $0.1(-0.4-0.6)$ \\
\hline Night-time symptom score $0-3$ & $-0.06(-0.19-0.07)$ & $-0.04(-0.13-0.04)$ & $-0.10(-0.24-0.03)$ & $0.05(-0.06-0.16)$ \\
\hline Symptom free days/weeks & $0.45(-0.31-1.21)$ & $1.35(0.62-2.08)$ & $1.29(0.29-2.27)$ & $0.21(-0.50-0.92)$ \\
\hline Rescue $\beta_{2}$-agonist use inhalations d day ${ }^{-1}$ & $-0.06(-0.71-0.59)$ & $-0.30(-1.05-0.45)$ & $-0.60(-1.14-0.06)$ & $0.90(-0.70-2.50)$ \\
\hline VAS symptom score mm & $-12.6(-22.7--2.6)^{*}$ & $-3.5(-15.2-8.2)$ & $10.1(-9.3-29.5)$ & $5.5(-10.0-21.1)$ \\
\hline Morning PEF & $15.2(6.4-24.0)^{\star}$ & $16.4(8.3-24.6)^{\star}$ & $4.9(-5.1-14.9)$ & $-1.3(-12.2-9.5)$ \\
\hline FEV1 L & $0.07(0.01-0.12)^{\star}$ & $-0.05(-0.15-0.06)$ & $-0.05(-0.13-0.03)$ & $-0.07(-0.20-0.05)$ \\
\hline
\end{tabular}

Data are presented as $\mathrm{n}$ or mean (95\% confidence intervals). PC20: provocative concentration causing a 20\% fall in forced expiratory volume in one second (FEV1); VAS: visual analogue scales; PEF: peak expiratory flow; AQLQ: Asthma Quality of Life Questionnaire; eNO: exhaled nitric oxide. *: $p<0.05$ ANOVA. 

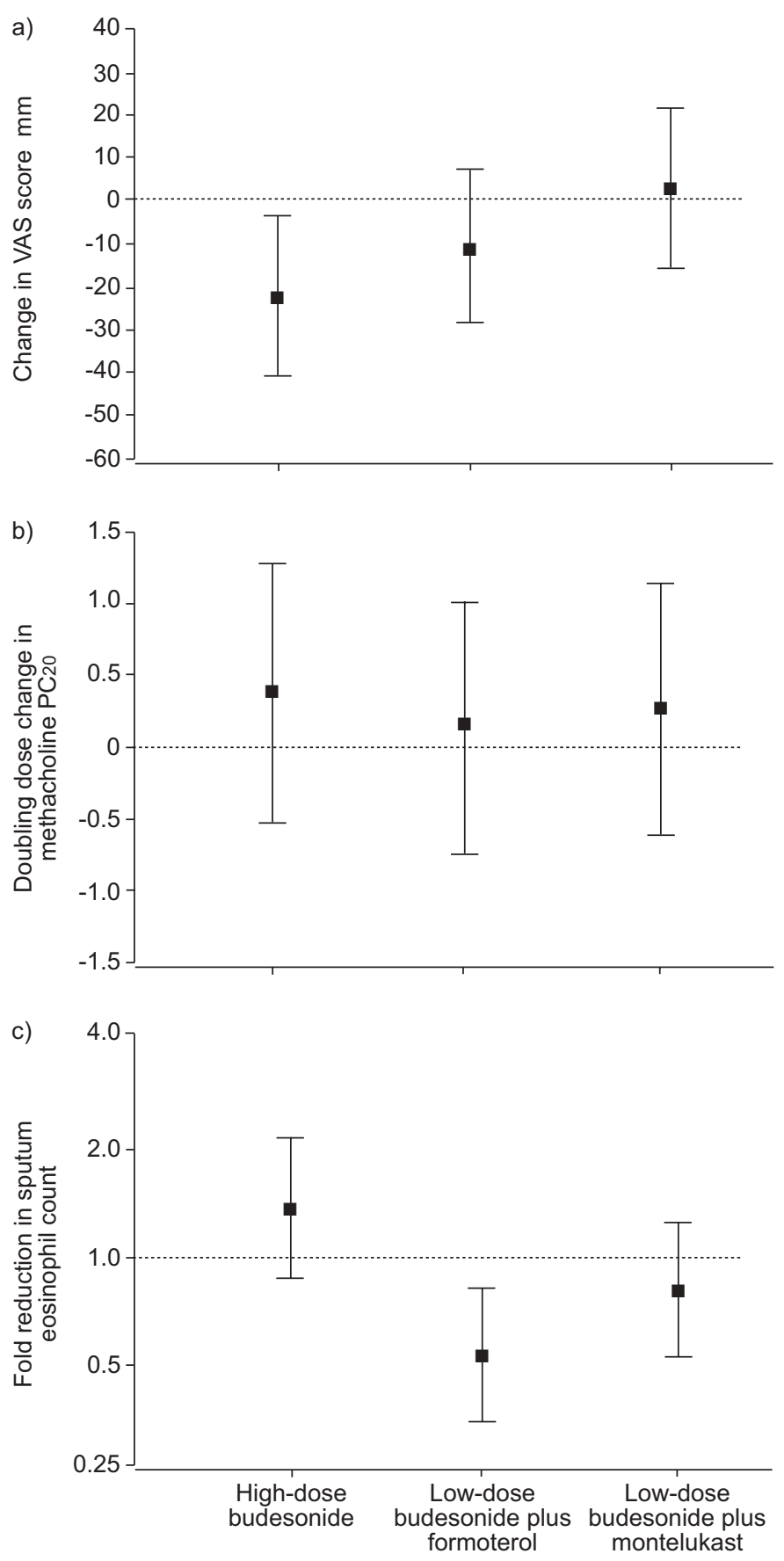

FIGURE 2. Mean net change in primary outcome compared with change in placebo. Vertical lines represent $95 \%$ confidence intervals. VAS: visual analogue scales; PC20: provocative concentration causing a $20 \%$ fall in forced expiratory.

studies [28]. The absence of a deleterious effect of formoterol on exacerbation frequency in earlier, appropriately powered studies $[2,3]$ suggests that the changes in sputum eosinophil count observed with formoterol treatment in the present study are not clinically relevant. However, the current authors could not discount the possibility that long-acting $\beta_{2}$-agonists are associated with an increase in the frequency of exacerbations that are particularly associated with increased eosinophilic airway inflammation and a reduction in the frequency of other events that are less dependent on airway inflammation [29].
The current authors have considered whether the increased eosinophilic inflammation that was observed with formoterol in the present study is due to patients reducing their inhaled corticosteroid dose because of improved control of symptoms. It is thought to be unlikely, since all treatment was given double blind and compliance was carefully assessed throughout the study. However, this may be an issue when inhaled corticosteroids and long-acting $\beta_{2}$-agonists are used separately in the community. Recent studies have shown that regular treatment with inhaled salbutamol in patients who are homozygous for Arg-Arg at position 16 leads to a deterioration in lung function [30] and is associated with an increased risk of asthma exacerbations [31]. In the present study, patients carrying this genotype responded less well to formoterol in terms of lung function and airway hyperresponsiveness, although the increased eosinophilic airway inflammation observed with formoterol was not confined to this group. However, due to the small numbers, the present authors cannot exclude the possibility that increased airway inflammation with regular $\beta_{2}$-agonists is a particular problem in patients with the Arg-Arg genotype; further studies are needed to investigate this possibility. The demonstration of an improved anti-inflammatory effect in homozygous Gln-27 patients was unexpected. The present authors recognise that multiple outcomes were studied in this report and this difference may have emerged by chance. Further work is required to determine whether this effect is real and to investigate the mechanism.

Previous studies of long-acting $\beta_{2}$ agonists [2-5] or montelukast $[6,32]$ given to patients who remain symptomatic despite low-dose inhaled corticosteroids have reported greater improvements in symptoms and morning PEF than those seen in the present study. In contrast, the current authors have demonstrated rather greater benefits from a high dose of inhaled corticosteroids than has previously been reported [25]. The present study involved shorter treatment periods than other studies, but this is unlikely to have biased the results in favour of inhaled corticosteroids since montelukast and formoterol reach their maximum effect earlier than inhaled corticosteroids $[2,6,32]$. The possibility that the masking of montelukast in a capsule reduced its bioavailability cannot be excluded, although there is no strong biological rationale for such an effect. A more likely explanation for these discrepancies between studies is the patient population studied. Unlike previous studies, the current study was not confined to recruiting subjects who demonstrated a marked acute bronchodilator response, a population who might be particularly likely to respond to a long-acting $\beta_{2}$-agonist [33]. The fact that the only other study that had entry criteria similar to the present study showed no significant improvement in FEV1, methacholine airway responsiveness, symptom scores or exacerbation rates when salmeterol was added to beclomethasone supports this interpretation [34]. The current authors did not find a relationship between bronchodilator response (or indeed any other of the variables measured) and the effect of treatment, although this was a relatively small study and the treatment effects were small so the power to demonstrate such a relationship was low.

In conclusion, the treatment over 4 weeks given in addition to low-dose inhaled corticosteroids resulted in modest benefits in 
patients who met the criteria for a step-up in treatment. Furthermore, the response to individual treatments appears to differ with the outcome variable, particularly with markers of eosinophilic airway inflammation. The current findings emphasise the complex relationship between different pathophysiological aspects of asthma. Further studies addressing the effects of treatment on a range of outcome variables in larger numbers of unselected patients are required.

\section{ACKNOWLEDGEMENTS}

The authors would like to thank the volunteers who participated in the study, C. Burns of the Leicester Mercury for help with patient recruitment, AstraZeneca for providing active and placebo inhalers, the Glenfield Hospital Pharmacy Dept for performing the randomisation, W. Monteiro for performing the cysteinyl leukotriene analyses, M. Hibbert for assistance with computer database design, and A. Wardlaw for his helpful advice.

\section{REFERENCES}

1 Neville RG, Pearson MG, Richards N, et al. A cost analysis on the pattern of asthma prescribing in the UK. Eur Respir J 1999; 14: 605-609.

2 Pauwels RA, Lofdahl CG, Postma DS, et al. Effect of inhaled formoterol and budesonide on exacerbations of asthma. Formoterol and Corticosteroids Establishing Therapy (FACET) International Study Group. $N$ Engl J Med 1997; 337: 1405-1411.

3 O'Byrne PM, Barnes PJ, Rodriguez-Roisin R, et al. Low dose inhaled budesonide and formoterol in mild persistent asthma: the OPTIMA randomized trial. Am J Respir Crit Care Med 2001; 164: 1392-1397.

4 Greening AP, Ind PW, Northfield M, Shaw G. Added salmeterol versus higher-dose corticosteroid in asthma patients with symptoms on existing inhaled corticosteroid. Allen \& Hanburys Limited UK Study Group. Lancet 1994; 344: 219-224.

5 Woolcock AJ, Lundback B, Ringdal N, Jacques LA. Comparison of addition of salmeterol to inhaled steroids with doubling of the dose of inhaled steroids. Am J Respir Crit Care Med 1996; 153: 1481-1488.

6 Laviolette M, Malmstrom K, Lu S, et al. Montelukast added to inhaled beclomethasone in treatment of asthma. Montelukast/Beclomethasone Additivity Group. Am J Respir Crit Care Med 1999; 160: 1862-1868.

7 Green RH, Brightling CE, McKenna S, et al. Asthma exacerbations and sputum eosinophil counts: a randomised controlled trial. Lancet 2002; 360: 1715-1721.

8 Smith AD, Cowan JO, Brassett KP, Herbison P, Taylor DR. Use of exhaled nitric oxide measurements to guide treatment in chronic asthma. N Engl J Med 2005; 352: 2163-2173.

9 Sont JK, Willems LN, Bel EH, van Krieken JH, Vandenbroucke JP, Sterk PJ. Clinical control and histopathologic outcome of asthma when using airway hyperresponsiveness as an additional guide to long-term treatment. The AMPUL Study Group. Am J Respir Crit Care Med 1999; 159: 1043-1051.

10 Juniper EF, Cockcroft DW, Hargreave FE. Histamine and methacholine inhalaltion tests: tidal breathing method.
Laboratory procedure and standardisation. 2nd Edn. Lund, Astra Draco, 1994.

11 Juniper EF, Guyatt GH, Epstein RS, Ferrie PJ, Jaeschke R, Hiller TK. Evaluation of impairment of health related quality of life in asthma: development of a questionnaire for use in clinical trials. Thorax 1992; 47: 76-83.

12 Pavord ID, Pizzichini MM, Pizzichini E, Hargreave FE. The use of induced sputum to investigate airway inflammation. Thorax 1997; 52: 498-501.

13 Brightling CE, Ward R, Woltmann G, et al. Induced sputum inflammatory mediator concentrations in eosinophilic bronchitis and asthma. Am J Respir Crit Care Med 2000; 162: 878-882.

14 Hall IP, Wheatley A, Wilding P, Liggett SB. Association of Glu 27 beta 2-adrenoceptor polymorphism with lower airway reactivity in asthmatic subjects. Lancet 1995; 345: 1213-1214.

15 Dewar JC, Wilkinson J, Wheatley A, et al. The glutamine 27 beta2-adrenoceptor polymorphism is associated with elevated IgE levels in asthmatic families. J Allergy Clin Immunol 1997; 100: 261-265.

16 Pavord ID, Brightling CE, Woltmann G, Wardlaw AJ. Noneosinophilic corticosteroid unresponsive asthma. Lancet 1999; 353: 2213-2214.

17 Kips JC, Inman MD, Jayaram L, et al. The use of induced sputum in clinical trials. Eur Respir J 2002; 20: Suppl. 37, $47 \mathrm{~s}-50 \mathrm{~s}$.

18 Vathenen AS, Knox AJ, Wisniewski A, Tattersfield AE. Time course of change in bronchial reactivity with an inhaled corticosteroid in asthma. Am Rev Respir Dis 1991; 143: 1317-1321.

19 Jatakanon A, Lim S, Chung KF, Barnes PJ. An inhaled steroid improves markers of airway inflammation in patients with mild asthma. Eur Respir J 1998; 12: 1084-1088.

20 British Thoracic Society; Scottish Intercollegiate Network. British guideline on the management of asthma. Thorax 2003; 58: Suppl. 1, i1-i94.

21 Kips JC, O'Connor BJ, Inman MD, Svensson K, Pauwels RA, O'Byrne PM. A long-term study of the antiinflammatory effect of low-dose budesonide plus formoterol versus high-dose budesonide in asthma. Am J Respir Crit Care Med 2000; 161: 996-1001.

$22 \mathrm{Li} \mathrm{X}$, Ward C, Thien F, et al. An antiinflammatory effect of salmeterol, a long-acting beta(2) agonist, assessed in airway biopsies and bronchoalveolar lavage in asthma. Am J Respir Crit Care Med 1999; 160: 1493-1499.

23 Wallin A, Sandstrom T, Soderberg M, et al. The effects of regular inhaled formoterol, budesonide, and placebo on mucosal inflammation and clinical indices in mild asthma. Am J Respir Crit Care Med 1999; 159: 79-86.

24 Roberts JA, Bradding P, Britten KM, et al. The long-acting beta2-agonist salmeterol xinafoate: effects on airway inflammation in asthma. Eur Respir J 1999; 14: 275-282.

25 Jatakanon A, Lim S, Barnes PJ. Changes in sputum eosinophils predict loss of asthma control. Am J Respir Crit Care Med 2000; 161: 64-72.

26 Aldridge RE, Hancox RJ, Robin TD, et al. Effects of terbutaline and budesonide on sputum cells and bronchial hyperresponsiveness in asthma. Am J Respir Crit Care Med 2000; 161: 1459-1464. 
27 Taylor DR, Sears MR, Herbison GP, et al. Regular inhaled beta agonist in asthma: effects on exacerbations and lung function. Thorax 1993; 48: 134-138.

28 Dennis SM, Sharp SJ, Vickers MR, et al. Regular inhaled salbutamol and asthma control: the TRUST randomised trial. Therapy Working Group of the National Asthma Task Force and the MRC General Practice Research Framework. Lancet 2000; 355: 1675-1679.

29 Reddel H, Ware S, Marks G, Salome C, Jenkins C, Woolcock A. Differences between asthma exacerbations and poor asthma control. Lancet 1999; 353: 364-369.

30 Israel E, Chinchilli VM, Ford JG, et al. Use of regularly scheduled albuterol treatment in asthma: genotype-stratified, randomised, placebo-controlled cross-over trial. Lancet 2004; 364: 1505-1512.
31 Taylor DR, Drazen JM, Herbison GP, Yandava CN Hancox RJ, Town GI. Asthma exacerbations during long term beta agonist use: influence of beta(2) adrenoceptor polymorphism. Thorax 2000; 55: 762-767.

32 Wilson AM, Dempsey OJ, Sims EJ, Lipworth BJ. Evaluation of salmeterol or montelukast as second-line therapy for asthma not controlled with inhaled corticosteroids. Chest 2001; 119: 1021-1026.

33 Green RH, Pavord ID. Leukotriene antagonists and symptom control in chronic persistent asthma. Lancet 2001; 357: 1991-1992.

34 Verberne AA, Frost C, Duiverman EJ, Grol MH, Kerrebijn KF. Addition of salmeterol versus doubling the dose of beclomethasone in children with asthma. The Dutch Asthma Study Group. Am J Respir Crit Care Med 1998; 158: 213-219. 